\title{
VARIOUS APPROACHES TO SOLVE UNCAPACITATED FIXED-CHARGE FACILITY LOCATION PROBLEM ON POSTAL NETWORK
}

\author{
Jozef Štefunko ${ }^{1}$, Radovan Madleňák ${ }^{2}$
}

\begin{abstract}
Availability and reliability of mail distribution services depends primarily on a network of postal operators. Choosing the appropriate layout of a network is key to maintaining quality while generating the lowest possible costs. This article focuses on creation of a postal network, based on an allocation model of an uncapacitated fixed-charge facility that considers road networks in the Slovak republic. A basic analysis of infrastructure is followed by incorporating service demands, and building and transport costs, in the chosen allocation model. Both construction and subsequent improvement heuristic algorithms are used to determine the number and location of postal sorting centers. The results are compared to find the lowest cost-generating solution. Even the best solution from available methods could be deemed sub-optimal as one does not know how close or how far the solution is from optimal. By varying the input variables, supported by a thorough analysis and consideration of future development of the transport network, one can improve efficiency in postal network operations.
\end{abstract}

JEL Classification Numbers: L87, R53, DOI: http://dx.doi.org/10.12955/cbup.v4.761

Keywords: postal network, allocation models, uncapacitated fixed-charge facility location, heuristic algorithms.

\section{Introduction}

The main business activity of a postal operator is reliable and regular delivery of postal items. Customers demand a guaranteed delivery time, while postal operators (like any other business entities) seek to maintain this parameter at minimal costs. Apart from processing technology, time and cost allocation for transport are critical factors in this business. Location of postal facilities and connections among them affect this component the most (Čorejová, Achimský, Fitzová, \& Kajánek, 1995). The number and location of postal processing centers in the postal transport network are determined, mainly by the logistics of the entire postal system. The decision of how many high level nodes and where to locate these is considered strategic and therefore, needs to be based on results of an optimization process.

\section{Discrete Location Models}

According to Černý and Kluvánek (1991), when considering transport networks, the simplest way to complete mathematical optimization is by graph theory. This method can describe and conceptualize transport networks and follow through with various tasks for formulation and solution. Such tasks include finding the optimal location of facilities.

Location models can be particularly useful in this case. Daskin (2013) claimed that the role of such mathematical models is to find answers to key questions, such as deciding on the number and location of facilities and how many demands will be covered by individual facilities. Where computational complexity of large allocation problems is high, the use of digital technologies is necessary to solve such a difficult task. Calculating the sub-optimal output value is considered a satisfactory approach to avoid time-consuming computations. Location models are application specific and bound to the particular problem under scrutiny. Consequently, no general location model exists that is appropriate for all potential or existing applications (Drezner \& Hamacher, 2002).

Allocation problems differ in the type of objective function and model of the environment in which they are addressed. Considering the transport networks (including postal), the use of discrete location modeling is convenient. One can classify such models according to their consideration of distance, as described by Madleňák (2005), as follows:

- Models based on maximum distance:

\footnotetext{
${ }^{1}$ Jozef Štefunko, Faculty of Operation and Economics of Transport and Communications, University of Žilina, jozef.stefunko@fpedas.uniza.sk

${ }^{2}$ Radovan Madleňák, Faculty of Operation and Economics of Transport and Communications, University of Žilina, radovan.madlenak@fpedas.uniza.sk
} 


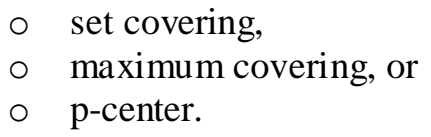

- Models based on total, or average distance:

o p-median,

- maxisum, or

fixed-charge facility location.

All mentioned discrete models require an underlying network and distance, or some other measure related to distance, as fundamental input to address problems. Adapting the basic definitions of graph theory, in this case, the model of environment (underlying network) for the transport network is conceptualized by a complete weighted graph (Equation 1):

$$
G=(V, E, c, w)
$$

where $V$ is the set of nodes representing possible facility locations; $E$ the set of edges representing connections between nodes; $c$ the label of edge $e$, an element of the $E$ value (length, time needed to cover the distance, costs needed to cover the distance, or other costs); and $w$ the weight of node $v$, an element of $V$, which represents the importance of nodes in a solved system (Janáček, 2006).

The issue examined in this article represents the use of location models, based on total and average distances. This includes, not only the cost for traveling distance, but also the cost for developing the facilities. In particular, research in this article focuses on the use of a model for a fixed-charge facility location.

\section{Uncapacitated Fixed-Charge Facility Location Model}

A model for an uncapacitated fixed-charge facility location (UFCFL) approaches the issue of a facility location, based on minimizing overall fixed costs as well as transport costs. This model works, according to Cornujelous, Nemhauser and Wolsey (1990), based on the following assumptions:

- Locating facility in candidate nodes might not imply the same fixed cost for each;

- Number of facilities to be located is not input into the model; and

- The theoretical capacity of a facility is unlimited; thus the demands are assigned based on the shortest distance.

The solution to this problem involves finding the optimal number and position of facilities within a graph, in a way that minimizes the total cost of the network. The assumed unlimited theoretical capacity of located facilities will ensure all demands are served. This model works with a set of variables as shown in Table 1.

\begin{tabular}{|c|c|c|c|}
\hline \multicolumn{2}{|r|}{ Input variables } & \multicolumn{2}{|r|}{ Decision variables } \\
\hline Notation & Description & Notation & Description \\
\hline$I$ & $\begin{array}{l}\text { set of nodes with demands to be } \\
\text { served }\end{array}$ & \multirow{3}{*}{$X_{j}$} & \multirow{3}{*}{$\begin{array}{l}=1 \text { if we locate facility at candidate } \\
\text { node } j \\
=0 \text { if not }\end{array}$} \\
\hline$J$ & $\begin{array}{l}\text { set of candidate nodes for facility } \\
\text { location }\end{array}$ & & \\
\hline$h_{i}$ & demand at node $i$ & & \\
\hline$d_{i j}$ & $\begin{array}{l}\text { distance between demand node } i \text { and } \\
\text { candidate node } j\end{array}$ & \multirow{3}{*}{$Y_{i j}$} & \multirow{3}{*}{$\begin{array}{l}\text { fraction of demands at node } i \text { that is } \\
\text { served by a facility at node } j\end{array}$} \\
\hline$f_{j}$ & $\begin{array}{l}\text { fixed costs of locating candidate } \\
\text { node } j\end{array}$ & & \\
\hline$\alpha$ & $\begin{array}{l}\text { costs per distance unit per demand } \\
\text { unit }\end{array}$ & & \\
\hline
\end{tabular}


The optimization problem can be formulated, according to Daskin (2013), as follows:

$$
\begin{gathered}
\sum_{j} f_{j} X_{j}+\alpha \sum_{i} \sum_{j} h_{i} d_{i j} Y_{i j} \\
\sum_{j} Y_{i j}=1 \quad \forall i \in I \\
Y_{i j} \leq X_{j} \quad \forall i \in I ; \forall j \in J \\
X_{j} \in\{0,1\} \quad Y_{i j} \geq 0 \quad \forall i \in I, j \in J
\end{gathered}
$$

The optimizing function (Equation 2) minimizes the total costs, which is the sum of the fixed facility costs and transport costs (total-demand-weighted distance multiplied by costs before distance unit for each demand unit). One constraint (Equation 3) requires each node, $i$, to be served. Another (Equation 4) ensures that demands at the node, $i$, cannot be assigned to a facility at a candidate node, $j$, unless the facility is located at node $j$. The latter constraints (Equation 5) are the integrality and non-negativity conditions.

\section{Algorithms for Solving UFCFL Problem}

Formulating an appropriate model is only one step in analyzing a location problem. More challenging than this is to find the suitable algorithm to establish the optimal solution. The first approach is to apply well-known algorithms, such as branch and bound. These algorithms work in most instances of location models, but are limited to small scale problems. In practice, scaled location models can have thousands of computations, which consume unacceptable volumes of computational memory and time (Garey \& Johnson, 1979).

To avoid this situation, or to shorten the consumption of computational resources, other methods have been defined to identify, at least, a "very good" solution. These methods are known as heuristic, and provide no guarantee of finding the optimal solution or the deviation from such. Therefore, the solution is regarded sub-optimal (Dresner \& Hamacher, 2002). Heuristic algorithms for solving the UFCL problem can be divided into two main groups, according to Madleňák (2005), as follows:

- Construction algorithms

Such algorithms apply "greedy" heuristic to obtain the subset of facilities from the initial set. This works on a sequential approach that begins by evaluating each location individually and from these, selecting the one that has the greatest impact for the objective. The facility at the location then becomes fixed. The next facility is located in a similar manner by calculation of the remaining possible locations and identifying the best improvement for the objective. Such an approach, when the initial set of facilities is empty, is known as the "ADD algorithm".

The "DROP algorithm" proceeds in reverse. The initial solution consists of facilities at every node and continues with removal of each sequential facility that minimizes the objective function the most. The removed facility is excluded until the end of the algorithm. Both algorithms terminate when the subsequent solution becomes inferior to the previous one. This approach provides a feasible solution with modest computational effort. However, results can usually be improved upon.

- Improvement algorithms

Such algorithms have been developed to improve the solution of construction algorithms. The well-known approach is "neighborhood" heuristic (Maranzana, 1964). The initial solution is divided into neighborhoods, which are sets of nodes that have demands assigned to each facility. Each potential facility relocation within each neighborhood is calculated and presented, based on the best improvement possible. After facilities are relocated, new neighborhoods are defined (if applicable) and the algorithm is repeated until no further changes can improve the solution.

Another improvement method was introduced by Teitz and Bart (1968) where the initial set of facilities is considered for relocation into unused locations. For each facility of the initial set, the best replacement node is identified and the pair with the best improvement for the overall objective is selected for relocation. When the improved solution is obtained and applied, demands are reassigned 
according to the shortest weighted-distance. The search process is repeated until no further improvement can be find. Such an approach is known as "exchange" or "substitution" algorithm. Depending on the nature of the initial solution, the potential impact of the entire facility removal can also be calculated prior to each substitution. The flowchart of substitution algorithm is shown in Figure 1.

\section{Input Network and Variables}

Knowledge of the environment was essential for designing and creating a postal network; especially in terms of its demographic and geographic parameters or administrative subdivisions. The most important, in this case, was the underlying infrastructure. The type of transport used in the postal sector depends entirely on the nature of postal items and transportation requirements. It is also influenced by the level of development of infrastructure that is potentially useable for transportation of postal items within each country. In Slovakia, it is the road transport, for its high availability and flexibility, that has the highest potential to be used in such a case (Madleňák \& Štefunko, 2015).

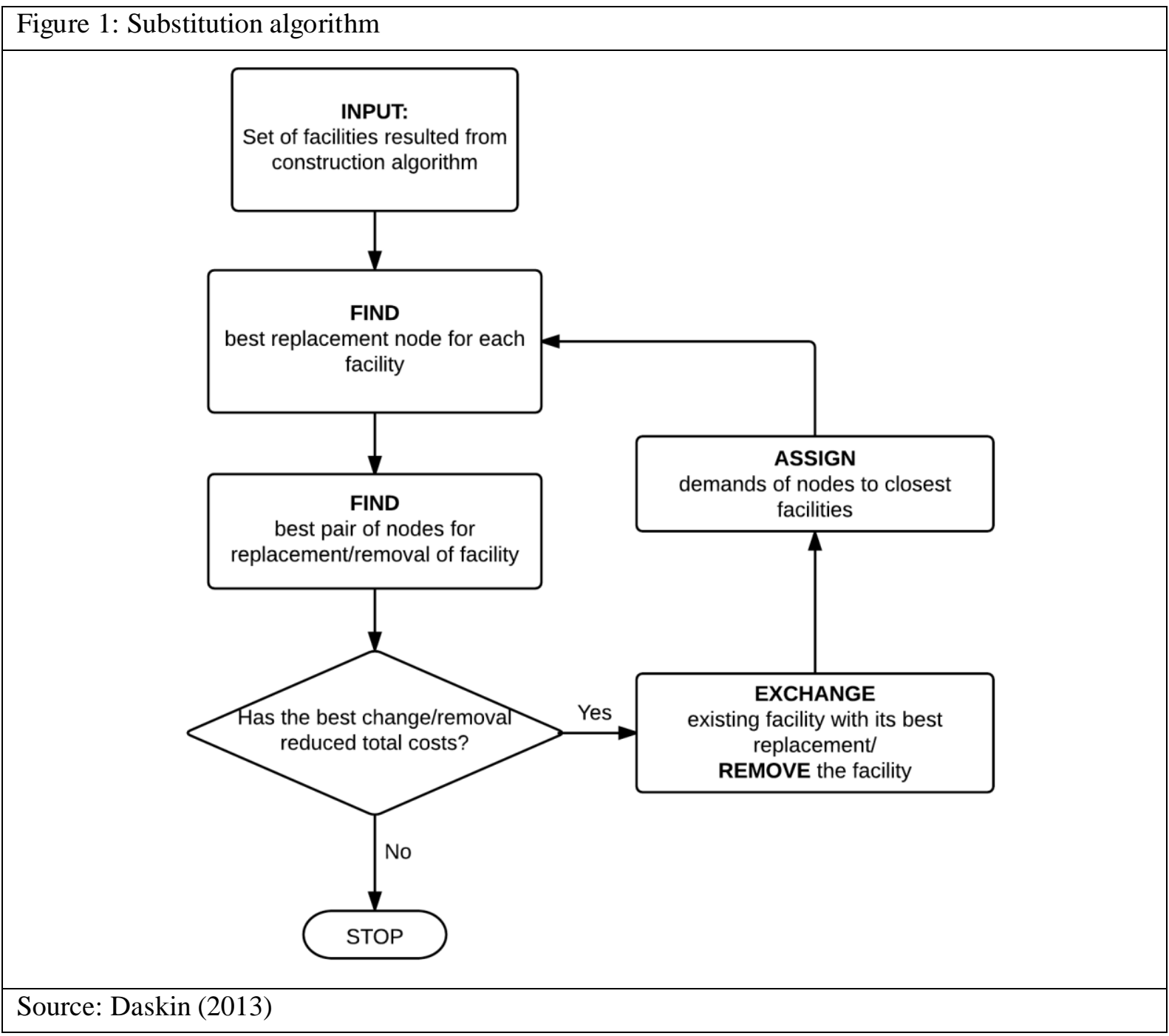

This study examined the idea of creating an entirely new postal network, based on existing road infrastructure. Therefore, it was not limited by parameters of existing networks or facility location. Only the existing three-level hierarchy operation was considered in this study. The lowest level consisted of regular post offices, which were connected to the middle-level modes only. The middlelevel nodes functioned as mail concentrators and ensured a certain degree of mail processing.

The postal items were then forwarded to high-level nodes, which were connected to each other. The process worked similarly in the opposite direction, i.e., from higher to lower level nodes. In this article, we focused on the location of highest level nodes. 
The basic model of the environment was achieved by using a weighted graph: $G=(V, H, c, w)$, as described earlier. This graph was built upon the basic territorial administrative division of the Slovak Republic. Nodes were placed at the administrative centers of these districts. Districts with the same administrative center were merged together. The resulting number of vertices was 71 , which were placed into a blank map of Slovakia in a way that maintained the similarity with their exact geographic location. The population of each district presented the number of demands to serve, and thus, determined the weight of the node.

The next step determined the set of edges to conceptualize in the node connections and how they were weight. Each edge weight was based on the shortest metric distance between adjacent nodes. The qualitative parameters of roads were not considered. The actual values were obtained by a Distance Matrix application created in Microsoft Office Excel using data from Google Maps. The resulting graph is shown on following figure (Figure 2).

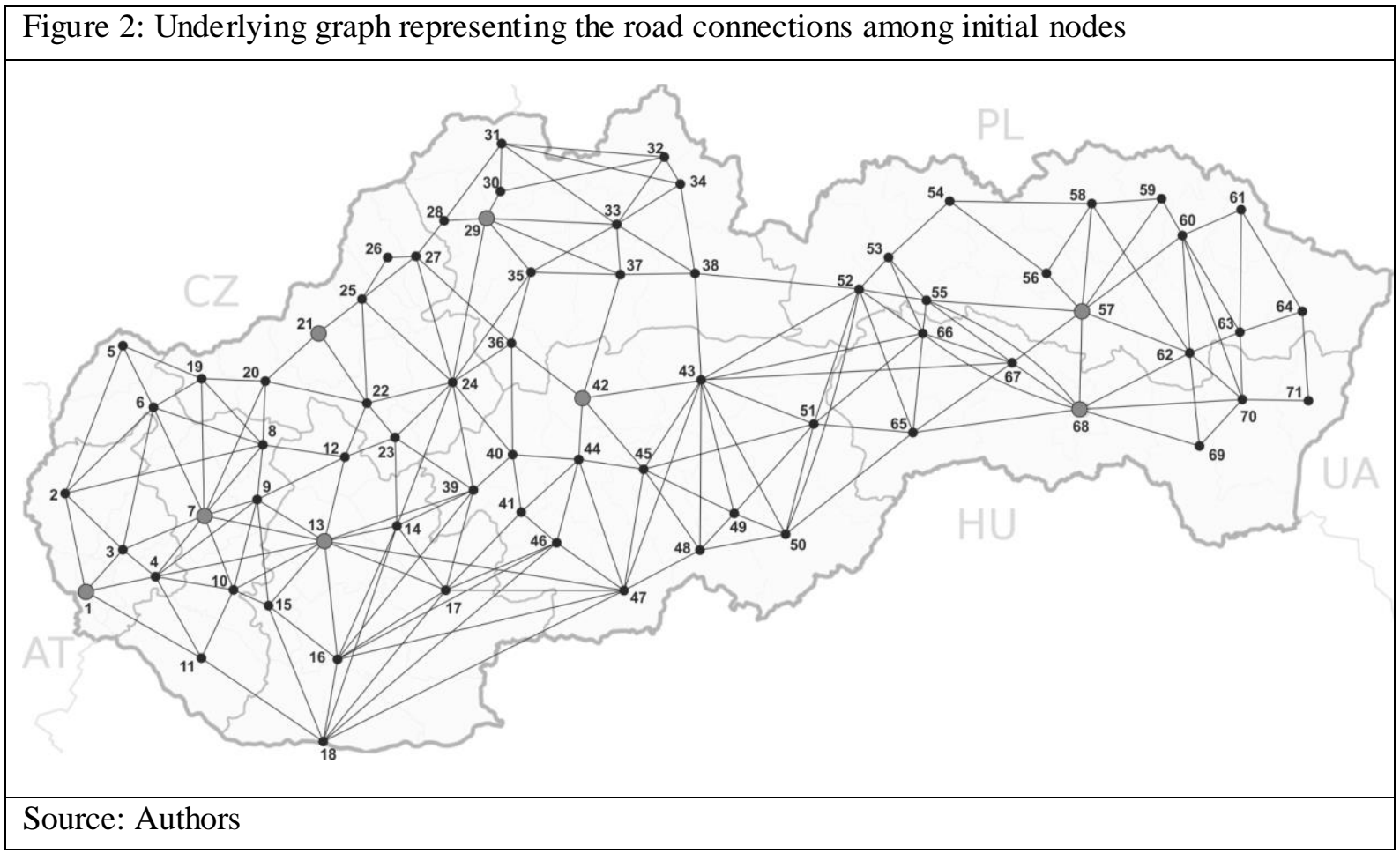

Since the aim was to solve the UFCFL problem, there were two more variables to be determined to obtain the solution. One was the "fixed costs" for the location and building of a facility at a certain node. We considered the uniform postal sorting center to have the same construction at all locations. The initial value of such a sorting center originated from similar projects that were implemented in comparable countries in recent years. This value was set to 800000 EUR. The specific parameters for each district were assessed by including the average costs of building, the land, and labor within the district. By comparing the national average values, we obtained weights for each district, and these were applied to the basic value to provide fixed costs for facilities in each district.

The remaining input variable was the "cost coefficient for each distance unit for every demand unit". First, the demand weight was calculated using available statistical data published by Universal Postal Union (2015). We used the average annual amount of mail per capita to obtained the value of 80.84, which was divided by the number of days in a year to obtain the daily amount of mail, i.e., 0.2215. The transport costs for each kilometer consisted of fuel consumption, vehicle wear, and depreciation. We also included rent and driver salary. The average value of transport costs was set to $0.22 \mathrm{EUR}$ for every kilometer for each vehicle with a load capacity of 12 tonne and with one driver, which generally constitutes the requirements for transport of postal items between middle and high-level nodes. The final value for the required coefficient was 0.04873 EUR for every demand-weighted kilometer.

The solution for the UFCFL problem proceeded. The computational complexity was shortened by programming using Visual Basic language to process the data in Microsoft Excel. 


\section{Results of UFCFL Model}

The application identified a solution for the UFCFL problem by using both previously mentioned construction algorithms, ADD and DROP, and by subsequent improvement through the substitution algorithm (neighborhood search algorithm programming in progress). The results for all four possible approaches are shown in Table 2.

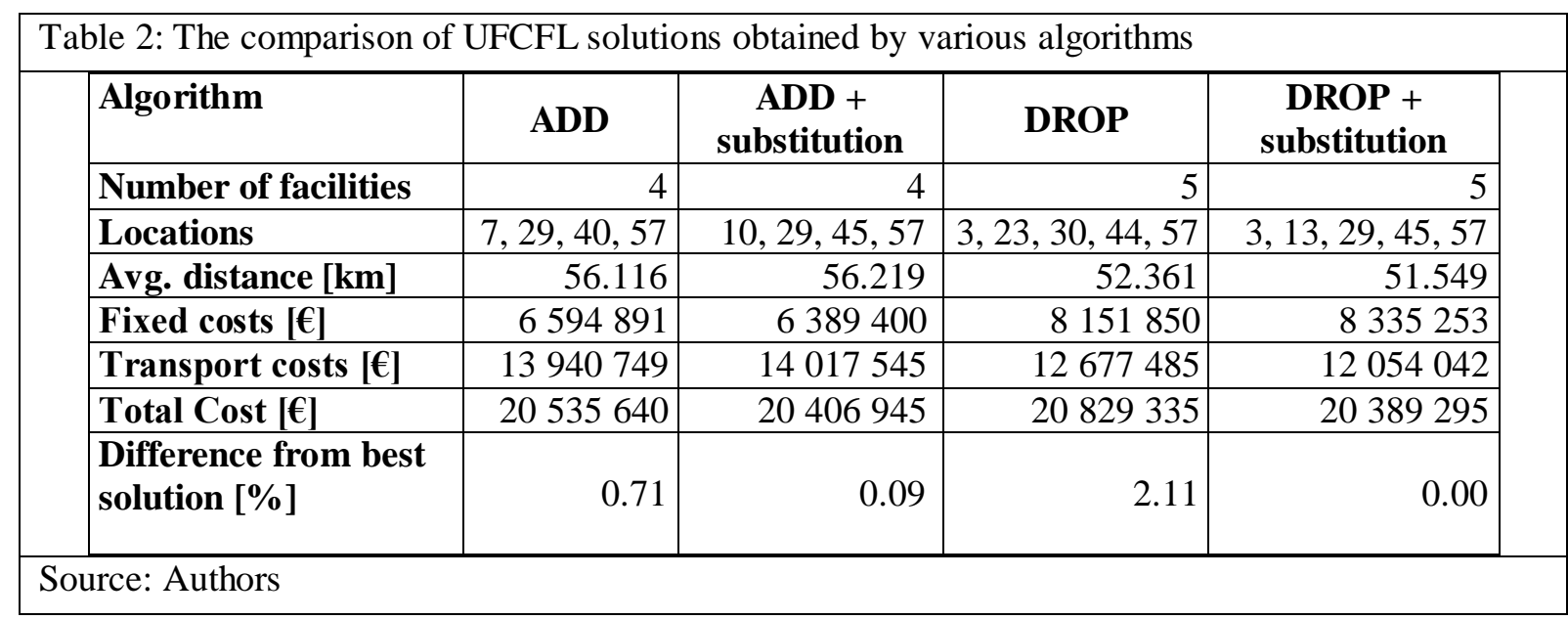

The results showed total costs of each variant were relatively similar. A difference in number of facilities resulted between the construction algorithms. Nevertheless, some locations were evaluated as optimal for both algorithms. The best (sub-optimal solution) in the model was obtained using the DROP algorithm followed by the substitution algorithm. This solution provided minimal value for the overall costs, weighted transport costs, and average-weighted distances. Due to considerably lower cost of the initial investment, the second best solution, which was produced by the ADD algorithm with the improvement substitution, was selected for further research. The detailed results for such a solution are presented below with the assignment of districts to individual facilities (Figure 3).

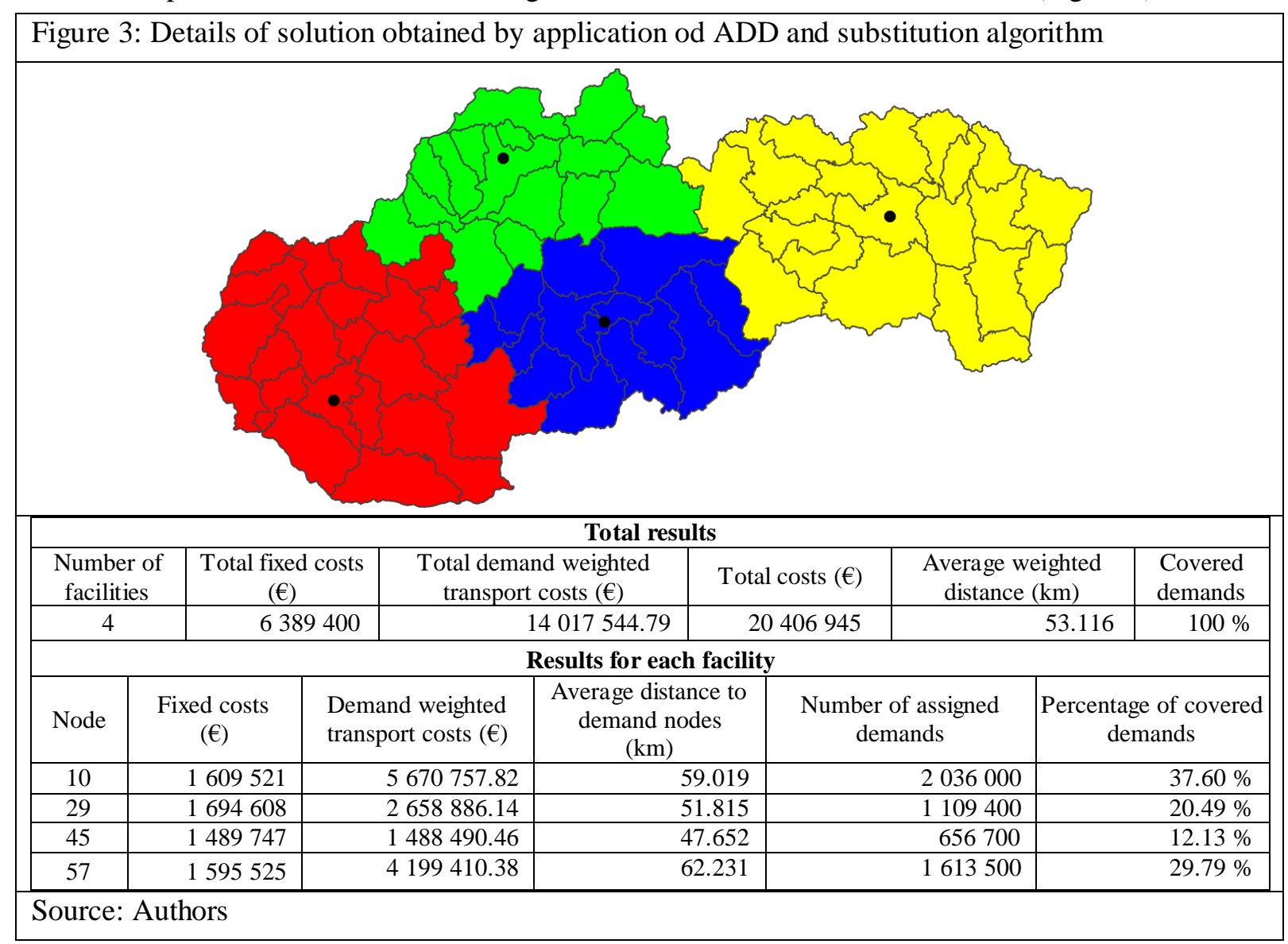




\section{Conclusion}

By applying different algorithms, we were able to solve the problem of uncapacitated fixed-charge facility location in a network composed of a chosen set of nodes and connections. The results were reliable and were obtained rapidly using programing in a universal application within Microsoft Excel. The identified facility locations with detailed parameters of service demands provided a model to help understand the behavior of the network; as well as compare the differences among applied algorithms.

Since the examined issue is exclusively dependent on input variables, further research could focus on identifying other locations more suitable than cities for building facilities. The number of districts (covering regions) appeared high for such a small territory like Slovakia. Merging districts (or identifying less or completely different ones) could further decrease computational time and provide more sophisticated output. A more thorough analysis of fixed costs and a demand weighted-distance coefficient could support the improvement of a sub-optimal solution. Implementing the future development of infrastructure or considering the railroad transport may also enhance results.

\section{Acknowledgments}

This contribution was undertaken as part of the research project 030ŽU-4/2015 KEGA Transformation of education in the field of postal technologies, networks, and services

\section{References}

Černý, J., \& Kluvánek, P. (1991). Základy matematickej teórie dopravy [Basics of mathematical theory of transport]. Bratislava, Slovakia: Veda.

Čorejová, T., Achimský, K., Fitzová, M., \& Kajánek, B. (1995). Projektovanie sietí v pošte I. [Designing networks in postal industry I.]. Žilina, Slovakia: Edičné stredisko [Series Centre] VŠDS. 11-16.

Cornuejols, G., Nemhauser, G. L., \& Wolsey, L. A. (1990). The Uncapacitated Facility Location Problem. Discrete Location Theory. Chapter 3. New York, USA: Wiley. 119-171.

Daskin, M. S. (2013): Network and discrete location: Models, algorithms and applications (Second ed.). Hoboken, NJ: John Wiley \& Sons. 235-260.

Dresner, Z., \& Hamacher, H. W. (2002). Facility Location; Applications and theory. Berlin, Germany: Springer. 81-107.

Garey, M. R., \& Johnson, D. S. (1979). Computers and Intractability: A Guide to the Theory of NP-Completeness. New York, USA: W. H. Freeman and Co.

Janáček, J. (2006). Optimalizace na dopravních sitích [Optimization on transport networks] Žilina, Slovakia: EDIS.

Madleňák, R. (2005). Algoritmy vhodné pre optimalizáciu najvyššej úrovne poštovej prepravnej siete [Algorithms suitable for optimization of highest level of postal transport network]. Doprava a Spoje, 1(1) [Transport and Communications, 1(1)]. Retrieved March 4, 2016, from http://fpedas.uniza.sk/dopravaaspoje/index.php

Madleňák, R., \& Štefunko, J (2015). Allocation of postal network facilities, based on existing road infrastructure. Central Bohemia University International Conference Proceedings 2015 Innovations in Science and Education. Prague, Czech Republic: CBU. 75-81.

Maranzana, F. E. (1964). On the Location of Supply Points to Minimize Transport Costs. Journal of the Operational Research Society, 15. 261-270. DOI:10.1057/jors.1964.47

Teitz, M. B, \& Bart, P. (1968). Heuristic methods for estimating generalized vertex median of a weighted graph. Operations research, 16. Maryland, USA: INFORMS. 955-961. Retrieved from http://dx.doi.org/10.1287/opre.16.5.955

Universal Postal Union (2015). Global and regional estimates. Retrieved from: http://pls.upu.int/pls/ap/ssp_report.main? p_language $=$ AN\&p_choice $=$ BROWSE 